\title{
Traffic Operations on Rural Two-Lane Highways: A Review on Performance Measures and Indicators
}

\section{Authors: Ahmed Al-Kaisy, Amirhossein Jafari, Scott Washburn, Tapio Lutinnen, and Richard Dowling}

This is a postprint of an article that originally appeared in Transportation Research Record on May 2018. The final version can be found at https://doi.org/10.1177/0361198118774743.

Al-Kaisy, Ahmed, Amirhossein Jafari, Scott Washburn, Tapio Lutinnen, and Richard Dowling. "Traffic Operations on Rural Two-Lane Highways: A Review on Performance Measures and Indicators." Transportation Research Record: Journal of the Transportation Research Board 2672, no. 15 (May 22, 2018): 66-74. doi:10.1177/0361198118774743. 


\title{
Traffic Operations on Rural Two-Lane Highways: a Review on Performance Measures and Indicators
}

\author{
Ahmed Al-Kaisy PhD, PE, Professor* \\ Department of Civil Engineering \\ Montana State University \\ 213 Cobleigh Hall, Bozeman, MT 59717 \\ Phone: (406) 994-6116, Fax: (406) 994-6105 \\ Email: aalkaisy@ce.montana.edu \\ Amirhossein Jafari, PhD Candidate \\ Department of Civil Engineering \\ Montana State University \\ 422 Roberts Hall, Bozeman, MT 59717 \\ Phone: (406) 580-6041 \\ Email: amirhossein.jafari@msu.montana.edu
}

Scott Washburn, PhD, PE, Professor

Department of Civil and Coastal Engineering

University of Florida

365 Weil Hall, Box 116580

Gainesville, Florida 32611

Phone: (352) 392-9537

Email:swash@ce.ufl.edu

Tapio Lutinnen, Dr., Professor

Department of Civil and Environmental Engineering

Aalto University, Finland

Email: tapio.luttinen@ aalto.fi

Richard Dowling PhD, PE, Senior Principal Engineer

Kittelson \& Associates, Inc.,

Oakland, CA

Email: rdowling@kittelson.com

* Corresponding Author

November 2017

Word counts: $6142($ text $)+3 \times 250($ table $)=6892$ word equivalents 


\begin{abstract}
Two- lane highways constitute a large proportion of the highway system in the US, particularly in rural areas. Performance evaluation on those highways is the basis for planning, upgrade and improvement programs. Such evaluations are conducted using performance measures that should ideally be correlated to performance determinants on those highways. Unlike other highway facilities, two-lane highway performance is notably affected by the platooning phenomenon, which is believed to be a function of traffic level and passing opportunities. Over the last couple of decades, several studies have addressed performance measures on two-lane highways, and are mainly driven by the reported limitations of the current measures used by the Highway Capacity Manual (HCM). This review aims at summarizing the performance measures that have been published in the literature or used in practice both in the US and abroad. The review started with an historical overview of the HCM performance measures since its inception in 1950. The review then discussed the most important criteria that are desired for performance measures to be more effective in describing performance, before it presents the review results for measures that have been proposed in literature or reported as being used in practice. Finally, a subjective assessment of all performance measures against the set of criteria outlined earlier in the article is presented. The review presented in this paper provides information that is valuable for practitioners and researchers in understating the alternative measures in assessing performance on two-lane highways and the limitations and merits associated with those measures.
\end{abstract}

Keywords: Two-lane highways, operational analysis, performance measures. 


\section{INTRODUCTION}

Two-lane, two-way highways constitute a large proportion of the highway system, particularly in rural areas. The unique characteristic that separates two-lane highways from other uninterrupted flow facilities is that passing occurs on the opposing lane of traffic. There should be adequate gap and sight distance in the opposite direction of traffic that a passing maneuver could occur. Passing opportunities decrease as flow rate and geometric restrictions increase. Lack of passing opportunities typically results in formation of platoons with trailing vehicles subject to additional delay.

The Level of Service (LOS) is a qualitative measure used by the HCM to show the quality of traffic flow on a highway facility. Currently, the HCM uses a scale from A to F to show the LOS, with $\mathrm{A}$ defined as best and $\mathrm{F}$ defined as worst condition for traffic flow. Performance measures are used to assess operations and LOS. On two-lane highways, they are intended to reflect the level of freedom for drivers to select their desired speeds and pass slow moving vehicles. Measuring performance is important for operational analysis and for upgrade and improvement projects. A low Level of Service (LOS) on a section of two-lane highway may be improved by adding a passing lane or expanding the route into a continuous three lane section or a multilane highway.

Operational analysis on two-lane highways in the U.S. and Canada (and some other countries outside North America) is usually conducted using the procedures outlined in the HCM (1). In the most recent edition of the HCM (1), average travel speed (ATS) and percent time spent following (PTSF) are used for evaluating performance on class I two-lane highways. Class I highways include major intercity routes, daily commuter routes, and major links in state or national highway network. ATS refers to average speed of all vehicles moving through the highway measured at a point. The PTSF is defined as "the average percentage of travel time that vehicles must travel in platoons behind slower vehicles because of an inability to pass" (1). PTSF is also used for class II two-lane highways which involve highways that serve as access routes to class I facilities as well as scenic and recreational routes. On those highways, motorists do not necessarily expect to travel at high speeds. Due to difficulties in measuring the PTSF in the field, the HCM recommends using a surrogate measure, calculated as the percentage of vehicles following other vehicles with headways smaller than 3 seconds. The third measure, Percent Free Flow Speed (PFFS), is used for evaluating performance on class III highways following recommendations from Washburn et al. (2). It is the ratio of average travel speed to free flow speed. Class III highways are two-lane highways serving moderately developed areas. They may include portions of class I and class II highways that pass through small towns or developed recreational areas. Table 1 shows the LOS criteria for two-lane highways in the $2016 \mathrm{HCM}(1)$.

TABLE 1 LOS Criteria for Two-Lane Highways (1)

\begin{tabular}{|c|c|c|c|c|}
\hline \multirow{2}{*}{ LOS } & \multicolumn{2}{|c|}{ Class I Highways } & Class II Highways & Class III Highways \\
\cline { 2 - 5 } & ATS (mi/hr) & PTSF (\%) & PTSF (\%) & PFFS (\%) \\
\hline A & $>55$ & $\leq 35$ & $\leq 40$ & $>91.7$ \\
\hline B & $>50-55$ & $>35-50$ & $>40-55$ & $>83.3-91.7$ \\
\hline C & $>45-50$ & $>50-65$ & $>55-70$ & $>75.0-83.3$ \\
\hline D & $>40-45$ & $>65-80$ & $>70-85$ & $>66.7-75.0$ \\
\hline E & $\leq 40$ & $>80$ & $>85$ & $\leq 66.7$ \\
\hline
\end{tabular}


Several studies reported limitations in the current performance measures used by the HCM (3-14). The main performance measure PTSF is limited in that it is difficult to measure in the field, is not compatible with the service measures of other facilities, does not describe the extent of congestion, and is not very useful in other analyses (e.g. economic, environmental, etc.). PTSF is also not a good performance measure for indicating if improvements should be made to a highway that has low volumes but a high percentage of heavy vehicles and a few passing opportunities. $A T S$, on the other hand, is not very informative about the efficiency of the highway. Since the analysis section of a two-lane highway facility is usually several miles long, there could be many changing conditions, such as posted speed limit and roadway alignment that affect ATS, yet it is not related to varying traffic conditions. The PFFS, an indicator of speed reduction due to traffic, can easily be measured in the field, however, it is not very sensitive to flow level for the uncongested traffic regime. Therefore, adding a passing lane was not found to tangibly affect this performance measure as reported by Al-Kaisy and Freedman (3).

A number of alternative performance and/or service measures for two-lane highways have been proposed in the literature. Most of the studies that proposed new performance measures were driven by the obvious limitations of the HCM performance measures used. This paper provides a review of alternative performance measures that have been proposed in the literature or reported as part of today's practice. All these measures are intended for estimating performance in a directional traffic stream, i.e. in one direction of a two-lane two-way highway.

\section{HCM PERFORMANCE MEASURES ON TWO-LANE HIGHWAYS: HISTORICAL OVERVIEW}

The HCM 1950 (15) was the first document introducing an analytical method for capacity analysis on two-lane highways. Practical capacity, which corresponds to the capacity under reasonable driving conditions, was used in this manual to assess the operating conditions on two-lane highways. Operating speed was the indicator for measuring the practical capacity. The concept of level of service was presented in the second edition of the HCM in 1965 (16). Operating speed and volume to capacity (v/c) ratio were used to estimate the level of service on two-lane highways. In 1985, the HCM introduced percent time delay (PTD) for measuring performance on two-lane highways besides average travel speed (17). It refers to the percentage of time that vehicles are delayed and trapped in platoons due to inability to pass slower vehicles. Delay refers to situations where drivers travel at speeds lower than their desired speeds. Headway threshold of 5 seconds was used to estimate the PTD in the field. The fourth edition of the HCM introduced PTSF which is a similar measure to PTD and refers to the percent of time vehicles are following other vehicles on two-lane highways (18). The percentage of vehicles with headways less than 3 seconds was used as a surrogate measure for PTSF in this edition of the HCM. The following edition of the HCM was released in 2010 (19) and introduced a new classification for two-lane highways: classes I, II and III. Besides PTSF and ATS, the percent free flow speed (PFFS) was the new measure introduced in this edition for operational analysis of class III two-lane highways. The most recent edition of the HCM was released in 2016 (1). The analytical methodology including performance measures in this edition is similar to that in the 2010 edition. 


\section{WHAT CONSITUTES A GOOD PERFRORMANCE MEASURE ON TWO-LANE HIGHWAYS?}

Ideally, performance measures used for traffic operations and capacity analysis on any highway facility should meet the following criteria (5):

1. Performance measure should reflect the perception of road users on the quality of traffic flow. It is a common understanding that platooning and lack of passing opportunities (and its associated delay) primarily affect the motorists' perception of the quality of service on twolane highways.

2. Performance measure should be easy to measure and estimate using field data. Specifically, it is expected that the prospective performance measure can be estimated in the field using conventional data collection methods used by highway agencies and the professional community. While some spatial performance measures are more difficult to observe in the field (e.g. density, average travel speed), it has been an accepted practice to estimate those measures using conventional data collection techniques at point locations.

3. Measure should correlate to traffic and roadway conditions in a meaningful way. On two-lane highways, the prospective performance measure should closely correlate to the platooning phenomenon (and passing opportunities) as well as to traffic level in a logical and meaningful way.

4. It is recommended that the prospective measure be compatible with performance measures used on other facilities. This criterion may be hard to satisfy as it is expected that different aspects of traffic operations are perceived as most important by drivers on different highway facilities. For example, while platooning on two-lane highways is a major determinant of the quality of operation, it is not a major factor in determining the quality of operations on other facilities.

5. Performance measure should be able to describe both uncongested and congested conditions. While this requirement is applicable to all highway facilities per the definition of the LOS scheme, it has been perceived to have less significance on two-lane highways, since these facilities are rarely congested and are usually upgraded to four lanes at traffic levels well below capacity.

6. Measure should be useful in analyses concerning traffic safety, transport economics, and environmental impacts. Increasingly, the capacity analysis procedures have been used in supporting the aforementioned analyses. To be of use in safety analyses, the prospective measure should correlate well to traffic exposure. On the other hand, for economic and environmental impact analyses, the prospective measure should be useful in estimating delay and its associated fuel consumption and tailpipe emissions.

The six criteria above consider the common operational objectives of most highway agencies, namely: mobility, productivity, safety, reliability and environmental impacts.

\section{REVIEW RESULTS}

This study identified many performance measures for two-lane highways that are proposed in the literature or reported of being used in practice. In this section, performance measures used by the 
HCM are presented first followed by those that have seen application in other countries, and finally, alternative measures that have been proposed in the literature.

\section{HCM Performance Measures}

The Highway Capacity Manual has been the principal reference for performing capacity analyses in the US and Canada since its inception in 1950. Therefore, the performance measures used by the current edition of the HCM largely represent the current practice in the US and Canada. As stated earlier in this article, three performance measures are used by the current HCM procedures for two-lane highways: percent time spent following (PTSF), average travel speed (ATS) and ATS as a percent of free-flow speed (FFS).

Percent-time-spent-following (PTSF): this performance measure has been in use since the fourth edition of the HCM that was published in 2000 (18). PTSF is defined as "the average percentage of travel time that vehicles must travel in platoons behind slower vehicles because of an inability to pass." (18). While the PTSF concept correlate well to the platooning phenomenon, the major determinant of performance on two-lane highways, it is almost impractical to measure in the field. Given this limitation in using PTSF, the HCM suggests using the percentage of headways less than 3 seconds as a good estimate for PTSF using field data. However, while PTSF by definition is a spatial measure, i.e. measured over a stretch of two-lane highways, the percentage of headways less than 3 seconds can only be measured at a point location.

Average travel speed (ATS): The vast majority of two-lane highways can be thought of as "uninterrupted flow facilities", thus enjoying relatively higher travel speeds. This is particularly true for the HCM class I highways, which represent important arterials and major collectors in rural areas. On these highways, ATS has long been used by the HCM as a performance measure with the premise that average speed is affected by traffic level and, thus, the amount of platooning due to limited passing opportunities. However, two-lane highways involve most of highway classifications, have a wide range of geometric standards, and consequently, a wide range of operating speeds. Therefore, using average speed alone may not provide enough information about the level of traffic performance (in the absence of a reference point) to make performance comparison across sites practical. ATS is also used as a performance measure for two-lane highways in Brazil (20). A recent survey of practice found that average travel speed is perceived to be the most relevant traffic flow aspect to two-lane highway operations by HCM users (21).

ATS as a percent of FFS: This performance measure has been in use since the HCM fifth edition published in 2010 for use on class III two-lane highways (19). Using ATS as a percentage of freeflow speed was viewed as a good indicator of the amount of speed reduction due to traffic and the amount of vehicular interaction in the traffic stream. However, evaluations using field data in the US, Egypt and Spain $(6,8,9)$ showed that the speed measures did not exhibit good correlations with platooning variables compared to other performance measures investigated in these studies. Further, Luttinen (5) reported on an older study by Kiljunen \& Summala in 1996 which proposed the use of $A T S / F F S$ as a performance measure on Finnish two-lane highways. 


\section{Performance Measures Used in Other Countries}

In this section, the major performance measures used in other countries are presented and discussed. HCM performance measures that found applications in practice outside the US are not covered in this discussion.

In their article on the German experience, Brilon and Weiser (22) reported that the current German Capacity Handbook (22) utilizes density as the primary service measure for two-lane highways. The rationale for using density as a performance measure on two-lane highways in Germany is that efficiency is given preference over user experience (perception) of the quality of service (22). Further, this performance measure is compatible with other facility types, mainly freeways and multi-lane highways, when those highway types are analyzed as part of a larger system. For this purpose, density is calculated as the ratio of traffic volume and the ATS of just passenger cars (i.e., $A T S_{p c}$ ). Average speed of passenger cars is measured over a longer stretch of highway, averaged over both directions. Truck speeds are not very sensitive to increases in traffic volume, but traffic volume is the main factor affecting the ATS of passenger cars (22). In their investigation of two-lane highway performance measures, Al-Kaisy and Karjala (6) argued that average travel speed of passenger cars may more accurately describe speed reduction due to traffic, since passenger car speeds are more affected by high traffic volumes than heavy vehicle speeds.

The $v / c$ ratio, or degree of capacity utilization, has been used as the main performance measure on two-lane highways in Japan, China and Denmark $(24,25,26)$. It is important to note that the two-lane expressways in Japan are different from the conventional two-lane highways in the U.S. and most other countries in that they have limited access (no at-grade intersections) and a median barrier present in all sections (24). Further, the $v / c$ ratio has been used as an additional performance measure in Sweden (27). This performance measure was also used for estimating the level of service along with operating speed in the second edition of the HCM (16).

Followers density (FD) is another performance measure, which was originally adopted by the South African National Roads Agency more than a decade ago $(12,28)$ and was later investigated in other studies $(6,8,9,11,29)$. Follower density is defined as the product of $P F$ and traffic density; therefore, this measure is derived using two important flow characteristics: traffic flow and density. Again, $P F$ is estimated using time headway, which is a microscopic flow characteristic. Follower density provides a better indication for warranting highway upgrades and improvements. Besides HCM performance measures, the Oregon Department of Transportation (ODOT) has used followers density in operational analysis of two-lane highways in recent years for the obvious advantage of capturing the effect of platooning and traffic level (30). Table 2 shows the LOS criteria as a function of follower density for class I, and II highways that was developed by Oregon DOT.

TABLE 2 LOS Criteria for Two-Lane Highways (30)

\begin{tabular}{|c|c|c|}
\hline \multirow{2}{*}{ LOS } & Class I Highways & Class II Highways \\
\cline { 2 - 3 } & Follower Density (veh/mi/lane) & Follower Density (veh/mi/lane) \\
\hline A & $\leq 2$ & $\leq 2.5$ \\
\hline B & $>2-3.5$ & $>2.5-4.0$ \\
\hline C & $>3.5-6$ & $>4.0-6.5$ \\
\hline D & $>6.0-9.0$ & $>6.5-10.0$ \\
\hline E & $>9.0$ & $>10.0$ \\
\hline
\end{tabular}




\section{Alternative Performance Measures Proposed in Literature}

Given the reported limitations in the current HCM performance measures (3-14), several alternative performance measures have been proposed by studies here in the US and in other countries.

A study by Al-Kaisy and Karjala (6) investigated a new speed-related performance measure among other performance measures on two-lane highways. The new measure is calculated as the average speed of passenger cars $\left(\mathrm{ATS}_{\mathrm{PC}}\right)$ divided by the free-flow speed of passenger cars

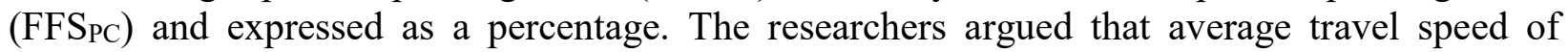
passenger cars may more accurately describe speed reduction due to traffic, since passenger car speeds are more affected by high traffic volumes than heavy vehicle speeds. Further, using ATS as a percentage of free-flow speed was viewed as a good indicator of the amount of speed reduction due to traffic and the amount of vehicular interaction in the traffic stream. However, evaluations using field data showed that the speed measures did not exhibit good correlations with platooning variables as compared to other performance measures investigated in this study. Later studies by Hashim and Abdel-Wahed (8) and Moreno et al. (9) reported similar results using field data in Egypt and Spain. In his study on PTSF in Finland, Luttinen (5) reported on another old study by O.K. Normann, who suggested the use of speed differences between successive vehicles on twolane highways among other proposed performance measures.

A couple of studies in the literature proposed the use of passing maneuvers in measuring performance on two-lane highways. The platooning phenomenon on two-lane highways and the associated delay are directly related to passing opportunities and the ability of platoon vehicles to pass slower vehicles and improve their speeds. As such, a few performance measures were proposed for assessing performance on two-lane highways that are related to passing maneuvers.

A study by Morrall and Werner (31) proposed the use of overtaking ratio as a supplementary indicator of the level of service on two-lane highways. This measure is obtained by dividing the number of passes achieved by the number of passes desired. According to the study, the number of passes achieved is the total number of observed passes for a given two-lane highway, while the number of passes desired is the total number of passes for a two-lane highway with continuous passing lanes with similar vertical and horizontal geometry. The overtaking ratio considers the effect of percentage of no-passing zones and passing lanes. The researchers showed that the effect of passing lanes as measured by overtaking ratio is greater than percent time delay used by the 1985 HCM. Overtaking ratio, along with the average number of passes per vehicle, were also proposed by O.K. Norman, as reported by McLean (32), and Luttinen (5).

Another measure that has been used extensively both in practical applications as well as in published research is time headway, a major microscopic traffic flow characteristic. For various practical reasons, time headway has been used solely for identifying platoons using empirical traffic data and field measurements. One important reason for using time headway is that this measure can readily be extracted from the output of conventional traffic recorders, which have the ability to provide raw data (i.e., timestamp records for individual vehicle arrivals). The second equally important reason is the fact that time headway is a good indicator of the interaction between successive vehicles in the traffic stream and, consequently, in determining the status of a vehicle being in a following mode (i.e. being part of a vehicular platoon).

Most of the proposed headway-related measures involves the estimation of the percentage of headways less than a pre-specified cut-off value, a measure called in recent studies as percent followers (PF). The percent of headways less than 3 seconds has been used by the HCM as a 
surrogate measure for PTSF using field data (1). A few recent studies have examined this along with other proposed performance measures to evaluate their suitability for use on two-lane highways $(6,8,9,11,28-30)$. This performance measure does not necessarily reflect the effect of traffic level, i.e. there could be a two-lane highway with low traffic volume but still a high percentage of short headways. Therefore, when used alone, this measure could be misleading in highway improvement and upgrade decisions. Various headway cut-off values were proposed to estimate the percentage of vehicles in following mode in the traffic stream $(12,13,29)$.

Besides PF, i.e. the percent of short headways in a traffic stream, a few other measures have been proposed in the literature that are associated with more than one traffic stream parameter, and as such, they are referred to in this discussion as compound measures. The merit of using compound measures is the fact that those measures usually combine the advantages of more than one indicator of traffic performance on two-lane highways (e.g., amount of platooning and traffic level). One such measure that was proposed in the literature is follower flow, which was investigated by the South African National Roads Agency (12). It is defined as the hourly rate of vehicles in following mode that pass a point along a two-lane highway. This measure can easily be estimated as the product of $P F$ and flow rate. Follower flow was investigated among several other performance measures in the development of the current South African two-lane highway methodology.

Penmtsa et al. (29) proposed another compound measure for Indian two-lane highways under mixed traffic condition. The new measure is called number of followers (NF), which represents the number of vehicles moving in the same lane of two-lane highways with gaps less than $2.6 \mathrm{~s}$. This measure showed a strong correlation with traffic volume. Penmtsa et al. (29) argued that NF alone is not able to identify the congestion condition on a highway network. Therefore, number of followers as a proportion of capacity (NFPC) was introduced as a new performance measure. The new measure exhibited a very strong correlation with traffic volume and it was found to explain the quality of traffic flow in a better way.

Another compound measure that was proposed in the literature is percent impeded (PI). This measure was originally proposed by Al-Kaisy and Freedman (33) and was later investigated by Hashim and Abdel-Wahed (8), Ghosh et al. (34), and Moreno et al. (9). PI is defined as percentage of vehicles impeded by slower-moving vehicles in a directional traffic stream measured at a point location. PI is calculated as the probability of desired speeds being greater than the average speed of platoon leaders multiplied by the percent of vehicles with headways less than a pre-specified threshold value. For establishing the distribution of desired speeds, vehicles with headway more than 8 seconds were used by Al-Kaisy and Freedman (33). Platoon leaders were used as a representative sample of slow moving vehicles. This measure is derived using flow and speed characteristics.

Percent impeded was further used to develop other compound measures. Impeded Flow which shows the hourly rate of vehicles impeded by slow-moving vehicles, i.e. platoon leaders, was suggested by Al-Kaisy et al. (35). It is calculated as the product of PI and the hourly rate of traffic flow. They also proposed Impeded Density, which refers to the number of vehicles impeded per mile per lane in one direction of travel. It is calculated as the product of PI and traffic density. These measures along with other performance measures were investigated by Al-Kaisy et al. (35) using field data from two-lane highways in Montana, Idaho, Oregon and North Carolina. Among all compound measures, follower flow followed by follower density exhibited highest correlations with traffic variables. 
Freedom of flow is another performance measure proposed for use on two-lane highways (36). Polus and Cohen (36) used the $\mathrm{M} / \mathrm{M} / 1$ queuing to model vehicular platoons on two-lane highways. In their approach, a platoon is considered as a queue system with random arrivals (vehicles joining the back of queue), random departures (vehicles passing platoon leader), and a single processing channel. To identify platooned vehicles, the researchers used a 3 -second follower headway threshold. In their research, two proposed traffic parameters were introduced: traffic intensity and freedom of flow. Similar to queuing analysis, traffic intensity $(\rho)$ in the context of platoon analysis refers to the ratio between the average time spent in the first position when waiting for an appropriate gap and the average inter-arrival times at the back of the queue. On the other hand, freedom of flow $(\eta)$ refers to the ratio between the time of undisturbed driving (between platoons) and the time interval in which the driver is in first position behind a slower moving vehicle while waiting to pass. This ratio may reflect the perception of tension experienced by drivers in a more faithful way. Freedom of flow can be estimated using equation 1 below.

Where:

$$
\eta=\frac{N_{o}}{\rho}
$$

$$
\begin{array}{ll}
\eta & =\text { Freedom of flow } \\
\rho & =\text { Traffic intensity } \\
N_{o} & =\text { Average number of headways between platoons }
\end{array}
$$

\section{PRELIMINARY ASSESSMENT OF PERFORMANCE MEASURES}

In this section, an initial qualitative assessment of the surveyed alternative performance measures is presented. The HCM performance measures will also be included in this assessment to help in understanding the merits of the proposed alternative measures. As stated before, it is desired for prospective performance measures on two-lane highways to meet the set of criteria discussed earlier in this study. Table 3 summarizes all performance measures discussed in this study and the degree to which each measure satisfies the aforementioned six criteria. In this subjective assessment, each performance measure is evaluated against the six criteria independently (i.e., assessed assuming it's used solely for measuring performance on two-lane highways). It is important to remember that those criteria do not have the same significance when it comes to conducting two-lane highway operational analysis. For example, to easily measure performance in the field may have more weight than supporting environmental impact analysis. As the objective of this research is to examine performance measures rather than to recommend a particular measure for operational analysis on two-lane highways, no weights were assigned to the six evaluation criteria.

At a glance, it can be clearly shown that no single measure largely satisfied all evaluation criteria and that each measure satisfied some criteria to a higher degree but scored low on other criteria. While this is applicable to almost all performance measures included in this evaluation, the following observations can be made:

1. The two major HCM performance measures on two-lane highways, PTSF and ATS, do not reasonably satisfy most of the six evaluation criteria.

2. Aside from being easy to measure in the field, speed-related measures scored generally low on all other criteria except for supporting economic and (to a lesser degree) environmental analyses. 
3. Performance measures based on passing maneuvers scored notably low on most of the evaluation criteria.

4. Compound measures involving headway and either density or flow rate showed higher degree in satisfying the six criteria particularly follower density and impeded density.

The above discussion suggests that coming up with a single performance measure that satisfactorily meets all criteria may prove to be very difficult, and therefore, it may be advantageous to use more than one performance measure in describing performance on two-lane highways.

TABLE 3 Preliminary Assessment Matrix of Performance Measures on Two-Lane Highways

\begin{tabular}{|c|c|c|c|c|c|c|c|c|c|}
\hline \multirow[b]{2}{*}{$\begin{array}{c}\text { Performance } \\
\text { Measure }\end{array}$} & \multirow[b]{2}{*}{$\begin{array}{c}\text { (1) } \\
\text { Road User } \\
\text { Perception }\end{array}$} & \multirow[b]{2}{*}{$\begin{array}{c}(2) \\
\text { Easy to } \\
\text { Measure }\end{array}$} & \multirow[b]{2}{*}{$\begin{array}{c}(3) \\
\text { Sensitive to } \\
\text { Road } \\
\text { Conditions }\end{array}$} & \multirow[b]{2}{*}{$\begin{array}{c}\text { (4) } \\
\text { Compatible } \\
\text { with Other } \\
\text { Facilities }\end{array}$} & \multirow[b]{2}{*}{\begin{tabular}{c}
\multicolumn{1}{c|}{$(5)$} \\
Describes \\
All Flow \\
Regimes
\end{tabular}} & \multicolumn{4}{|c|}{ (6) Support Other Analyses } \\
\hline & & & & & & 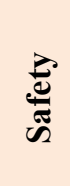 & 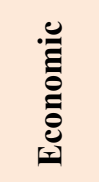 & 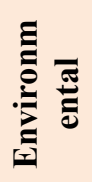 & 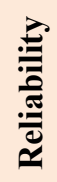 \\
\hline $\mathrm{HCM}-\mathrm{PTSF}^{\mathrm{a}}$ & $\mathrm{XXX}^{\mathrm{b}}$ & $\mathrm{X}$ & $\mathrm{X}$ & $\mathrm{X}$ & $\mathrm{X}^{\mathrm{c}}$ & $\mathrm{X}$ & $\mathrm{X}$ & $\mathrm{X}$ & $\mathrm{X}$ \\
\hline HCM - ATS & $\mathrm{X}$ & XXX & $\mathrm{X}$ & $\mathrm{XX}$ & $X^{c}$ & $\mathrm{X}$ & $\mathrm{XX}$ & $\mathrm{X}$ & $\mathrm{X}$ \\
\hline $\begin{array}{c}\mathrm{HCM}- \\
\text { (ATS/FFS) }\end{array}$ & $\mathrm{XX}$ & $\mathrm{XXX}$ & $\mathrm{XX}$ & $\mathrm{X}$ & $\mathrm{XX}^{\mathrm{c}}$ & $\mathrm{X}$ & $\mathrm{XXX}$ & $\mathrm{XX}$ & $\mathrm{X}$ \\
\hline $\mathrm{ATS}_{\mathrm{PC}}$ & $\mathrm{X}$ & $\mathrm{XXX}$ & $\mathrm{X}$ & $\mathrm{XX}$ & $\mathrm{X}$ & $\mathrm{X}$ & $\mathrm{XX}$ & $\mathrm{X}$ & $\mathrm{X}$ \\
\hline $\begin{array}{c}\text { ATS } S_{\mathrm{PC}} \text { as a } \\
\text { percent of FFS } \\
\text { of PCs } \\
\text { (ATS } S_{\mathrm{PC}} / \mathrm{FFS} \mathrm{SPC}_{\mathrm{PC}}\end{array}$ & $\mathrm{XX}$ & $\mathrm{XXX}$ & $\mathrm{XX}$ & $X$ & $\mathrm{XX}$ & $\mathrm{X}$ & XXX & $\mathrm{XX}$ & $\mathrm{X}$ \\
\hline Speed Variance & $\mathrm{X}$ & XXX & $\mathrm{X}$ & $\mathrm{X}$ & $\mathrm{X}$ & $\mathrm{XX}$ & $\mathrm{X}$ & $\mathrm{X}$ & $\mathrm{X}$ \\
\hline $\begin{array}{l}\text { Volume-to- } \\
\text { capacity }(\mathrm{v} / \mathrm{c}) \\
\text { ratio }\end{array}$ & $\mathrm{XX}$ & XXX & $\mathrm{XX}$ & $X$ & $\mathrm{XXX}$ & $\mathrm{XX}$ & $\mathrm{X}$ & $\mathrm{X}$ & $\mathrm{X}$ \\
\hline Traffic Density & $\mathrm{X}$ & XXX & $\mathrm{XX}$ & $\mathrm{XX}$ & XXX & $\mathrm{X}$ & $\mathrm{X}$ & $\mathrm{X}$ & $\mathrm{X}$ \\
\hline Overtaking ratio & $\mathrm{X}$ & $\bar{X}$ & $\mathrm{XX}$ & $X$ & $\mathrm{X}$ & $\mathrm{X}$ & $\mathrm{X}$ & $\mathrm{X}$ & $\mathrm{X}$ \\
\hline $\begin{array}{l}\text { Average \# of } \\
\text { passes per } \\
\text { vehicle }\end{array}$ & $\mathrm{X}$ & $\mathrm{X}$ & $\mathrm{XX}$ & $X$ & $\mathrm{X}$ & $\mathrm{XX}$ & $\mathrm{X}$ & $\mathrm{X}$ & $\mathrm{X}$ \\
\hline$\%$ followers $(\mathrm{PF})$ & $\mathrm{XX}$ & XXX & $\mathrm{XX}$ & $\mathrm{X}$ & $\mathrm{X}$ & $\mathrm{X}$ & $\mathrm{X}$ & $\mathrm{X}$ & $\mathrm{X}$ \\
\hline $\begin{array}{l}\text { Follower flow } \\
\text { (FF) }\end{array}$ & $\mathrm{X}$ & XXX & $\mathrm{XXX}$ & $X$ & $\mathrm{X}$ & $\mathrm{XX}$ & $\mathrm{X}$ & $\mathrm{X}$ & $\mathrm{X}$ \\
\hline $\begin{array}{l}\text { Follower density } \\
\text { (FD) }\end{array}$ & $\mathrm{XX}$ & XXX & $\mathrm{XXX}$ & $\mathrm{XX}$ & $\mathrm{X}$ & $\mathrm{XX}$ & $\mathrm{X}$ & $\mathrm{X}$ & $\mathrm{X}$ \\
\hline $\begin{array}{l}\text { Percent impeded } \\
(\mathrm{PI})\end{array}$ & XXX & $\mathrm{XX}$ & $\mathrm{XXX}$ & $X$ & $\mathrm{X}$ & $\mathrm{XX}$ & $\mathrm{X}$ & $\mathrm{X}$ & $\mathrm{X}$ \\
\hline $\begin{array}{l}\text { Impeded flow } \\
\text { (IF) }\end{array}$ & $\mathrm{X}$ & $\mathrm{XX}$ & XXX & $X$ & $\mathrm{X}$ & XX & $\mathrm{X}$ & $\mathrm{X}$ & $\mathrm{X}$ \\
\hline $\begin{array}{l}\text { Impeded density } \\
\text { (ID) }\end{array}$ & $\mathrm{XX}$ & $\mathrm{XX}$ & $\mathrm{XXX}$ & $\mathrm{XX}$ & $\mathrm{X}$ & $\mathrm{XX}$ & $\mathrm{X}$ & $\mathrm{X}$ & $\mathrm{X}$ \\
\hline Freedom of flow & $\mathrm{X}$ & $\mathrm{X}$ & $\mathrm{XX}$ & $\mathrm{X}$ & $\mathrm{XX}$ & $\mathrm{XX}$ & $\mathrm{X}$ & $\mathrm{X}$ & $\mathrm{X}$ \\
\hline
\end{tabular}

a - PTSF is estimated using flow rates in the analytical methodology and using percent followers (PF) as a surrogate measure for field estimation.

$\mathrm{b}-\mathrm{X}=$ hardly meeting criterion, $\mathrm{XX}=$ fairly meeting criterion, $\mathrm{XXX}=$ largely meeting criterion

$\mathrm{c}-$ Level of service $\mathrm{F}$ is not defined for any of the three HCM 2016 performance measures 


\section{SUMMARY}

The current study presented an overview of performance measures that have been used in practice or proposed in the literature for assessing performance on rural two-lane highways. A historical background on two-lane highway performance measures used by the highway capacity manual since its first edition was presented. Further, the most important desired criteria for effective performance measures were presented and discussed. The review involved the performance measures currently used by the Highway Capacity Manual (HCM), those that have been used in other countries, and other alternative performance measures proposed in the literature. The study concluded with assessing the degree each performance measure satisfies each of the criteria identified for effective performance measures. While subjective in nature, this preliminary assessment provides valuable information about the merits, or lack thereof, of a large number of performance measures identified in this study. Results suggest that no single measure largely satisfied all evaluation criteria and that each measure satisfied some criteria to a higher degree but scored low on other criteria. Therefore, coming up with a single performance measure that satisfactorily meets all criteria may prove to be very difficult, and it may be advantageous to use more than one performance measure in describing performance on two-lane highways.

\section{ACKNOWLEDGEMENT}

The authors would like to acknowledge the financial support provided for this study by the National Cooperative Highway Research Program.

\section{REFERENCES}

1. Transportation Research Board. Highway Capacity Manual. Sixth Edition, TRB, National Research Council, Washington, D. C., 2016.

2. Washburn, S., McLeod, S. and G.K. Courage. Adaptation of Highway Capacity Manual 2000 for Planning-Level Analysis of Two-Lane and Multi-Lane Highways in Florida, Transportation Research Record: Journal of the Transportation Research Board, No. 1802, 2002, pp. 62-68.

3. Al-Kaisy, A., and Z. Freedman. Empirical Examination of Passing Lane Operational Benefits on Rural Two-Lane Highways. Journal of Transportation Research Forum, Vol. 49, No. 3, 2010, pp. 53-68.

4. Dixon, M. P., S. S. K. Sarepali, and K. A. Young. Field Evaluation of Highway Capacity Manual 2000 Analysis Procedures for Two-Lane Highways. In Transportation Research Record: Journal of the Transportation Research Board, No. 1802, Transportation Research Board of the National Academies, Washington, D.C., 2002, pp. 125-132.

5. Luttinen, T. Percent Time-Spent-Following as a Performance Measure for Two-Lane Highways. Transportation Research Record 1776, Journal of the Transportation Research Board, TRB, National Research Council, Washington, D.C., 2001, pp. 52-59.

6. Al-Kaisy, A., and S. Karjala. Indicators of Performance on Two-Lane Rural Highways: An Empirical Investigation. Transportation Research Record: Journal of the Transportation Research Board, No. 2071, Transportation Research Board of the National Academies, Washington, D.C., 2008, pp. 87-97. 
7. Al-Kaisy, A. F., and C. Durbin. Estimating Percent Time Spent Following on Two-Lane Highways: Field Evaluation of New Methodologies. Presented at 86th Annual Meeting of the Transportation Research Board, Washington, D.C., 2007.

8. Hashim, I. and T.A. Abdel-Wahed. Evaluation of Performance Measures for Rural Two-Lane Roads in Egypt. Alexandria Engineering Journal, No. 50, 2011, pp.245-255.

9. Moreno, A., Llorca, C., Sayed, T., and A. Garcia. Field Evaluation of Traffic Performance Measures for Two-Lane Highways in Spain. Presented at 93rd Annual Meeting, Transportation Research Board, Washington, D. C., 2014.

10. Romana, M. G., and I. Pérez. Measures of Effectiveness for Level-of-Service Assessment of Two-Lane Roads: An Alternative Proposal Using a Threshold Speed. Transportation Research Record: Journal of the Transportation Research Board, No. 1988, Transportation Research Board of the National Academies, Washington, D.C., 2006, pp. 56-62.

11. Catbagan, J. and Nakamura, H. Evaluation of Performance Measures for Two-Lane Expressways in Japan. Transportation Research Record 1988, Journal of the Transportation Research Board, TRB, National Research Council, Washington, D.C., 2006, pp. 111-118.

12. Van As, C. The Development of an Analysis Method for the Determination of Level of Service on Two-Lane Undivided Highways in South Africa: Project Summary. South African National Roads Agency, Limited, Pretoria, 2003.

13. Al-Kaisy, A., Jafari, A. and S. Washburn. Following Status and Percent Followers on TwoLane Two-Way Highways: Empirical Investigation. Presented at 96th Annual Meeting of the Transportation Research Board, Washington, D.C., 2017.

14. Ibrahim, M., and O. C. Puan. Measuring Driver's Percent-Time-Spent-Following Using a Moving Video Recording Technique. Journal of Applied Mechanics and Materials, Vol. 567, pp. 736-741.

15. Highway Capacity Manual: Highway Research Board and Bureau of Public Roads, Washington, D.C., 1950.

16. Special Report 87: Highway Capacity Manual, 2nd ed. Highway Research Board, Washington, D.C., 1965.

17. Special Report 209: Highway Capacity Manual, 3rd ed. (1997 update). TRB, National Research Council, Washington, D.C., 1985.

18. Highway Capacity Manual, Fourth Edition, TRB, National Research Council, Washington, D. C., 2000.

19. Highway Capacity Manual. TRB, National Research Council, Washington, D. C., 2010.

20. Bessa, J.E. and J.R. Setti. Deviation of ATS and PTSF Functions for Two-lane, Rural Highways in Brazil. Presented at the 6th International Symposium on Highway Capacity and Quality of Service, 2011.

21. Al-Kaisy, A., Jafari, A. and S. Washburn. Performance Measures on Two-Lane Highways: Survey of Practice. Presented at 95th Annual Meeting of the Transportation Research Board, Washington, D.C., 2016.

22. Brilon, W., and F. Weiser. Two-Lane Rural Highways: The German Experience. Transportation Research Record 1988: Journal of the Transportation Research Board, TRB, National Research Council, Washington, D. C., 2006, pp. 38-47.

23. Handbuch fuer die Bemessung von Strassen (German Highway Capacity Manual). HBS 2001. German Road and Transportation Research Association, Cologne, 2005.

24. Nakamura, H. and Oguchi, T. An Investigation on Performance Measures for Two-Lane Expressways in Japan. Proceedings of the 5th International Symposium on Highway Capacity 
and Quality of Service. Vol.2: Technical Papers. Tokyo: Japan Society of Traffic Engineers, 2006, pp. 87-104.

25. Rong, J., Guo, J. and Zhou, R. Chinese Highway Capacity Research Studies and Applications. In H.N. \& Bang, K.L. (ed.), 6th International Symposium on Highway Capacity and Quality of Service - Country Reports. Stockholm: TRB and KTH, 2011, pp. 52-66.

26. Vejdirektoratet. Kapacitet og serviceniveau. Vejdirektoratet, Vejregelrådet. - Road Standards for Capacity and Level of Service (in Danish). 2010.

27. Trafikverket (2014). TRVMB Kapacitet och framkomlighetseffekter. TRV 2013:64343.

28. Van As, C. and A. Niekerk. The Operational Analysis of Two-Lane Rural Highways, 23rd Annual Southern African Transport Conference, Pretoria, South Africa, 2004.

29. Penmetsa, P., Ghosh, I., and S. Chandra. Evaluation of Performance Measures for Two-Lane Intercity Highways under Mixed Traffic Conditions. Journal of Transportation Engineering, Volume 141, issue 10, 2015, pp. 1-7.

30. Oregon Department of Transportation. Modeling Performance Indicators on Two-Lane Rural Highways: The Oregon Experience. Retrieved December 11, 2014, from http://www.oregon.gov/odot/td/tp/docs/reports/modelingperf.pdf

31. Morrall, J. F., and A. Werner. Measuring Level of Service of Two-Lane Highways by Overtakings. Transportation Research Record 1287, Journal of the Transportation Research Board, TRB, National Research Council, Washington, D. C., 1990, pp. 62-69.

32. McLean, J. Two-Lane Highway Traffic operations: Theory and Practice. Transportation Studies Volume 11, Gordon and Breach Science Publishers, 1989.

33. Al-Kaisy, A., and Z. Freedman. Estimating Performance on Two-Lane Highways: Case Study Validation of a New Methodology. Transportation Research Record 2173, Journal of the Transportation Research Board, TRB, National Research Council, Washington, D. C., 2011, pp. $72-79$.

34. Ghosh, I., Chandra, S. and Boora, A. Operational Performance Measures for Two-Lane Roads: An Assessment of Methodological Alternatives. 2nd Conference of Transportation Research Group of India (2nd CTRG), Agra, India, Procedia - Social and Behavioral Sciences 104, Elsevier, December 12-15, 2013, pp. 440 - 448.

35. Al-Kaisy, A., Jafari, A. and S. Washburn. Measuring Performance on Two-Lane Highways: Empirical Investigation. Presented at 96th Annual Meeting of the Transportation Research Board, Washington, D.C., 2017.

36. Polus, A. and M. Cohen. Theoretical and empirical relationships for the quality of flow and for a new level of service on two-lane highways. Journal of Transportation Engineering, Vol135, No. 6, 2009, pp. 380-385. 